\title{
1 How microfracture roughness can be used to 2 distinguish between exhumed cracks and in- situ flow paths in shales
}

15 Keywords:

14

\author{
Pluymakers, Anne * a), Kobchenko, Maya ${ }^{\text {a) }}$, and Renard, François a) b)
}
a) PGP, Departments of Physics and Geosciences, University of Oslo, postboks 1048, Blindern, 0316 Oslo, Norway

b) University Grenoble Alpes, ISTerre, 38000 Grenoble, France

* Corresponding author: A. Pluymakers, a.m.h.pluymakers@ @ys.uio.no, PGP, Department of Physics, University of Oslo, postboks 1048, Blindern, 0316 Oslo, Norway; +47 94423619

Maya Kobchenko: maya.kobchenko@fys.uio.no

François Renard: francois.renard@geo.uio.no

X-ray micro-tomography; fluid flow; faults; crack growth; Hurst exponent; shale gas 


\section{Abstract}

18 Flow through fractures in shales is of importance to many geoengineering purposes. Shales are

19 not only caprocks to hydrocarbon reservoirs and nuclear waste or $\mathrm{CO}_{2}$ storage sites, but also

20 potential source and reservoir rocks for hydrocarbons. The presence of microfractures in shales

21 controls their permeability and transport properties. Using X-ray micro-tomography and white

22 light interferometry we scanned borehole samples obtained from $4 \mathrm{~km}$ depth in the Pomeranian

23 shales in Poland. These samples contain open exhumation/drying cracks as well as intact vein-

24 rock interfaces plus one striated slip surface. At micron resolution and above tensile drying

25 cracks exhibit a power-law roughness with a scaling exponent, called the Hurst exponent $H$, of

26 0.3. At sub-micron resolution we capture the properties of the clay interface only, with $H=0.6$.

27 In contrast, the in-situ formed veins and slip surface exhibit $H=0.4-0.5$, which is deemed

28 representative for in-situ fractures. These results are discussed in relation to the shale

29 microstructure and linear elastic fracture mechanics theory. The data imply that the Hurst

30 roughness exponent can be used as a microstructural criterion to distinguish between exhumation

31 and in-situ fractures, providing a step forward towards the characterization of potential flow

32 paths at depth in shales. 
35 The roughness of natural fault surfaces does not only control many aspects of earthquake mechanics (Scholz, 2002), but is equally of importance for fluid flow through natural and

37 induced fractures (Brown, 1987; Noiriel et al., 2007; Fitts and Peters, 2013). Shales in particular

38 are studied for their importance as caprock to hydrocarbon reservoirs and $\mathrm{CO}_{2}$ plus nuclear waste storage sites, for which the lack of effective transport pathways is evidently paramount. In contrast, it is the efficiency of transport through existing and induced fractures and faults that controls the primary migration of hydrocarbons and the recovery of shale gas. Fault or fracture

42 roughness is an important control on transmissivity, especially in small aperture cracks (e.g. Fitts and Peters, 2013). Data on roughness of representative fault surfaces in shale rocks is however

44 lacking, mainly because of their fragile nature. Natural fault rocks in these lithologies weather 45 easily unless they are highly cohesive, which may occur when buried deeply, or by experiencing high strain and/or seismic slip. Investigations on natural low displacement faults, mainly on

47 (striated) fault planes in carbonate rocks, have shown that with increasing displacement there is a 48 slight decrease in roughness amplitude (Sagy et al., 2007; Brodsky et al., 2011). However, for 49 total displacements larger than $\sim 10 \mathrm{~m}$, common for major continental faults, there are no trends 50 found in roughness data (Candela and Renard, 2012). In this study we investigate low to no 51 displacement faults and fractures found in a shale drill-core. When using drill-core, fractures that 52 contain cement are easily identified as originating in the subsurface, but subsurface fractures are 53 not always cemented. Thus, one of the key challenges is to identify fractures present in-situ 54 compared to those that originate during sample recovery. Correct identification of in-situ 55 fractures will help to determine realistic flow-controlling properties for natural and induced 56 fractures in low-permeability shale formations, such as wall roughness and fracture aperture. It is 
57 difficult, if not impossible, to estimate absolute in-situ fracture apertures from borehole samples,

58 therefore our main focus lies on determining the roughness of fracture walls. In the present study,

59 we determine fracture roughness both of veins and decompression fractures of the Pomeranian

60 shales from Poland. Since vein formation occurs at depth, the topography of the vein-rock

61 interface is preserved even when samples are extracted from the subsurface. We use X-ray

62 microtomography and white light interferometry (examples shown in Figure 1) at multiple 2-D

63 pixel and 3-D voxel sizes, ranging from 0.1 to 25 micrometers, with sample sizes between 0.5 -

$647.5 \mathrm{~cm}$. Our data cover spatial scales in the range 0.5 micrometer to 5 centimeters, i.e. five orders

65 of magnitude. These different measurements provide us with information on how scale,

66 resolution, and method affect roughness values in a heterogeneous, fragile rock as shale. The

67 Polish Pomeranian shale has been selected because this formation is prospected for shale gas

68 exploration, even though not all data are yet available in the public domain (Schulz et al., 2010).

69 The core material we obtained originates from a borehole in northern Poland that reached 70 approximately $4 \mathrm{~km}$ depth, with a thermal maturity inside the gas window, and a depth that does

71 not exclude economic exploitation (even though currently exploitation at the borehole location is 72 not planned). 

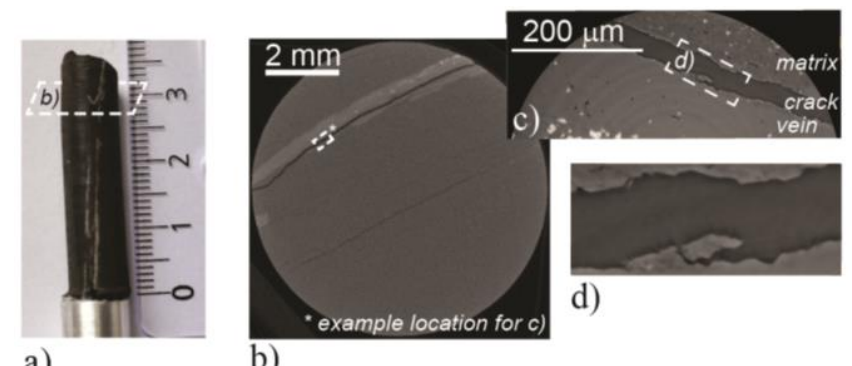

a)

b)
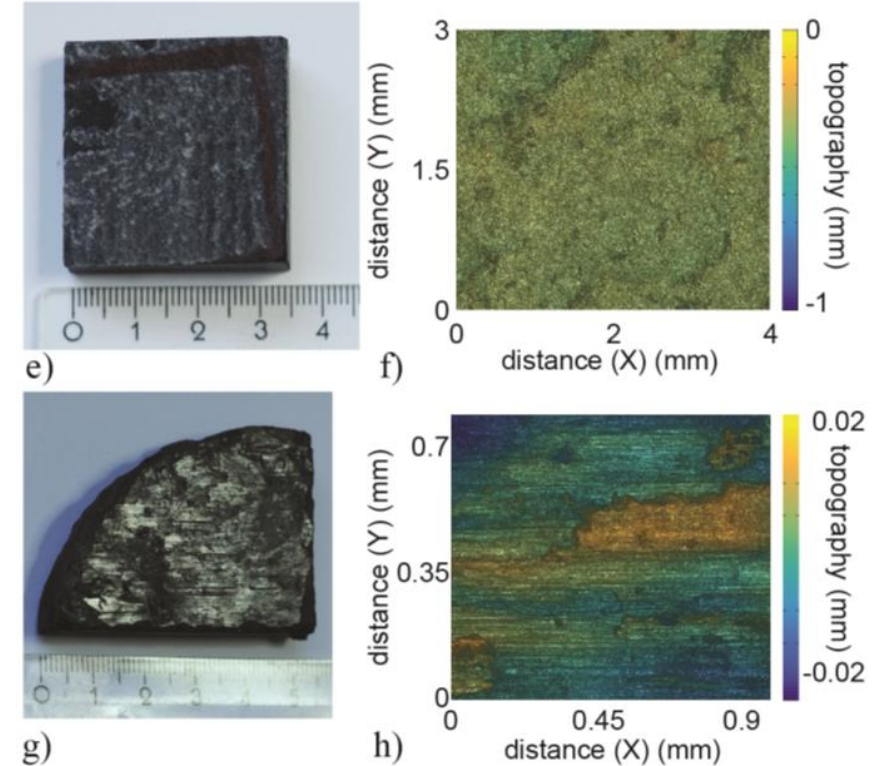

74 Figure 1. Examples of samples plus data. a-d) Sample SQ686.5-SS7 for X-ray microtomography. Veins and fracture parallel to the bedding. a) Photo. b) Low resolution X-Y slice of raw XCT data SQ686.5-SS7. Veins and fracture parallel to the bedding. c) Highest resolution X-Y slice of filtered data, scanned at the synchrotron at the ESRF, Grenoble. The approximate location is indicated in Figure b. Note that because the scans are made in different locations and at different resolutions, it is not possible to show exactly the same slice in b) and c). d) Zoom, location indicated in c), showing the roughness of the vein/air interface and the matrix/air interface. e)

81 Photo of slab with vein SQ617.15-SS17, analyzed with white light interferometry. f) Example of 82 white light interferometry data. g) Photo of the shiny slip surface of sample SQ698.0- SS20, also 83 analyzed with white light interferometry. h) Example of white light interferometry data.

84 The cracks are currently open, but there is no a priori information on opening mode or mechanism. The storage of the drill core at ambient conditions for several months prior to characterization was associated with dehydration of the drill core, visible through the

87 development of the open cracks investigated here. Consequently, it is plausible that these are related to sample drying, and we thus assume that all the open cracks investigated here are 
89 simple mode I fractures. The veins are sealed, cement-filled fractures, where the sealing

90 presumably occurred at depth. Due to the limitations of the cm-scale core provided, the

91 maximum length scale is up to multiple centimeters. This means that the fractures in question

92 here are microfractures from the perspective of engineers and geophysicists, but not for

93 geologists - for whom the term microfracture indicates a fracture that requires microscopy to

94 observe.

95 Table 1: Sample details.

\begin{tabular}{|c|c|c|c|c|}
\hline Stratigraphy & Lithostratigraphy & Sample code & $\begin{array}{l}\text { Analysis } \\
\text { method }\end{array}$ & Resolution / magnification \\
\hline \multirow{3}{*}{$\begin{array}{l}\text { Silurian - } \\
\text { Lower Wenlock } \\
\text { Sheinwood }\end{array}$} & \multirow[t]{3}{*}{ Pelplin Formation } & SQ617.15-SS17 & WLI & $5 x \& 20 x$ \\
\hline & & SQ629.55-SS16 & WLI & $5 x \& 20 x$ \\
\hline & & SQ631.45-SS15 & WLI & $2.4 \mathrm{x}$ to $40 \mathrm{x}$ \\
\hline \multirow{4}{*}{$\begin{array}{l}\text { Silurian - } \\
\text { Llandovery }\end{array}$} & Pasłęk Formation & SQ636.5-SS11 & $\mathrm{XCT}$ & $12.7 \mu \mathrm{m} / \mathrm{voxel}$ \\
\hline & \multirow[t]{3}{*}{ Jantar Member } & SQ682.2-SS9 & WLI & $5 x \& 20 x$ \\
\hline & & SQ685.65-SS7 & $\mathrm{XCT}$ & $0.16-1.7-7.8-25.7 \mu \mathrm{m} /$ voxel \\
\hline & & SQ689.3-SS5 & $\mathrm{XCT}$ & $24.5 \mu \mathrm{m} /$ voxel \\
\hline \multirow[t]{2}{*}{$\begin{array}{l}\text { Ordovician - } \\
\text { Caradocian }\end{array}$} & \multirow[t]{2}{*}{ Sasino Formation } & SQ698.0-SS20 & WLI & $2.5 \mathrm{x}$ to $100 \mathrm{x}$ \\
\hline & & SQ705.3-SS19 & $\begin{array}{l}\text { WLI, } \\
\text { XCT }\end{array}$ & $5 x \& 20 x \& 23.5 \mu \mathrm{m} /$ voxel \\
\hline
\end{tabular}

WLI stands for White Light Interferometer, and XCT for X-ray microtomography.

a) This is the slip surface.

\section{Methods}

\subsection{Sample description}

The Pomeranian shale is a dark-grey to black rock composed of approximately 50-70\% clay minerals and mica, $20-30 \%$ quartz, $1-10 \%$ carbonates, $1-10 \%$ organic matter, $1-7 \%$ pyrite plus minor amounts of barite, K-feldspar, plagioclase and kaolinite. We had access to a drill-core from approximately $4 \mathrm{~km}$ depth, located on one of the concessions of the Polish Oil \& Gas 
Company (PGNiG SA) in northern Poland. We obtained four smaller core samples for 3D X-ray microtomography scans (XCT, Table 1), and five open fracture or vein samples for 2D white light interferometry measurements (WLI, Table 1). Note that even though samples originated from different formations, the composition and structure of the shale was homogeneous throughout the $\sim 30 \mathrm{~m}$ long sampling interval. The samples for the tomography scans are $8 \mathrm{~mm}$ in diameter, and between 10 and $40 \mathrm{~mm}$ long (e.g. Figure 1a). In these cylindrical samples there are several calcite veins present, with a thickness from sub-mm up to $3 \mathrm{~mm}$. These core samples also contain several open cracks, with an aperture up to $2 \mathrm{~mm}$. Due to the fragility of the samples that contain bedding-perpendicular veins, we only obtained tomography cores in which the majority of the veins and cracks in the tomography samples are approximately bedding-parallel. Furthermore, using a white light interferometer, we scanned the surface of five slabs for which the drill core had split, exposing a thin (sub-mm) calcite vein (e.g. Figure 1e, f). For all samples except SQ705.3 the splitting occurred approximately perpendicular to the bedding. In this drillcore we also found one striated, mirror-like slip surface parallel to the bedding, which we also scanned with the white light interferometer (SQ698.0-SS20). All slabs were 35 to $75 \mathrm{~mm}$ long and 20 to $45 \mathrm{~mm}$ wide. Samples and imaging methods are listed in Table 1.

We have imaged two samples, the slip surface of SQ698.0-SS20 and its nearest non-slip neighbour, sample SQ705.3-SS19, with a Hitachi TM3000 (table-top) SEM with EDS capability in electron back-scatter mode (Figure 2a-f). On the slip surface (Figure 2a, b, c) the striations are widespread, though they are more pronounced in the calcite-rich parts than in the clay-rich matrix, and in the clay-rich matrix they are more pronounced than in the silica-rich matrix. The calcite-rich grains are elongated parallel to the striations (Figure 2a). The smooth surface is locally covered by fault gouge that matches the matrix composition, with grain sizes of tens of 
128 micrometers (Figure 2c). In the smooth clay-rich matrix, grains are rounded with a maximum

129 length of 1-2 $\mu \mathrm{m}$, whereas the more silica-rich matrix grains can be slightly coarser, up to $10 \mu \mathrm{m}$.

130 There is no visible pore space.

131 The undeformed sample SQ705.3-SS19 exhibited a channel structure exposing the undeformed 132 clay matrix. On the carbonate cover multiple barite crystals are present (Figure 2 d-e) with 133 crystal sizes of roughly 50-500 $\mu \mathrm{m}$. In the exposed undeformed matrix, the sub-micron clay 134 particles maintain their elongated crystal shape with grain lengths up to tens of micrometers, in 135 contrast to the clay particles on the slip surface of SQ698.0-SS20. Non-clay particles are oriented 136 randomly, and at 600x magnification there is visible pore space (up to $1 \mu \mathrm{m}$ in size, Figure $2 \mathrm{f}$ ).

137 We have also imaged a thin section of sample SQ685.65-SS7 using a regular optical microscope 138 (Figure 2g-h). This shows that the veins in this sample consist mainly of calcium carbonate 139 crystals, locally with groups of micron-sized oxides (black polygons in Figure 2g-h, probably 140 barite). The carbonate crystals cover the entire width of the vein and can exhibit lobate grain 141 boundaries. Along the edge of the veins there is also some fibrous calcite. The largest calcite 142 grains exhibit twinning. 


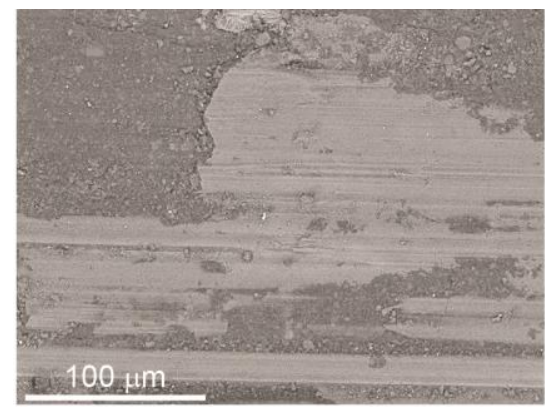

a)

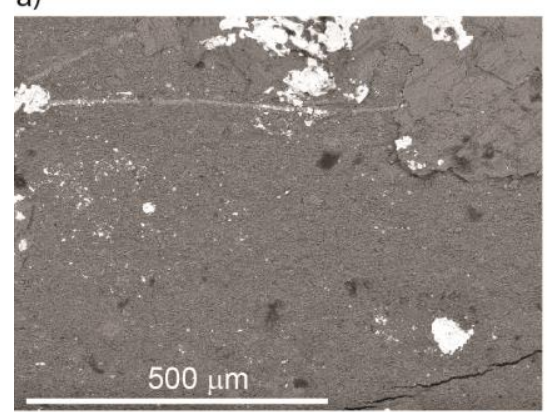

d)

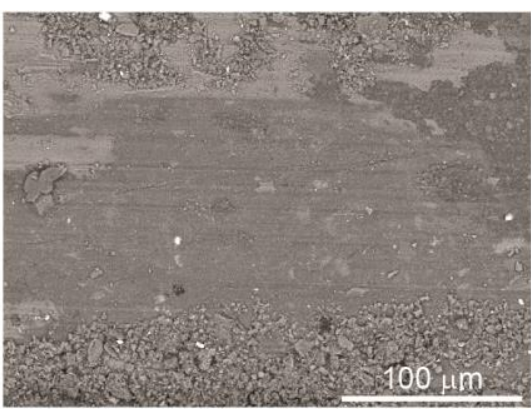

b)

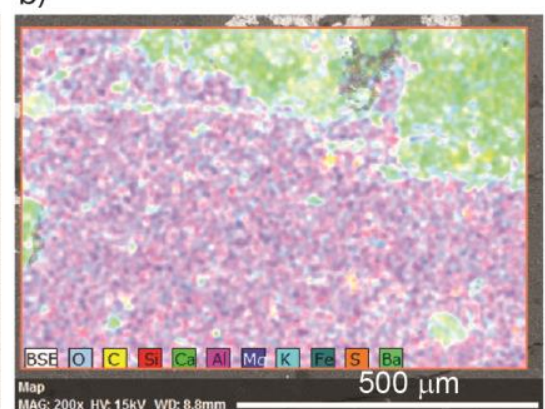

e)

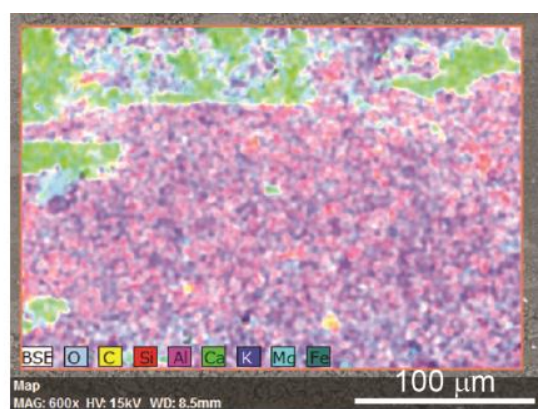

c)

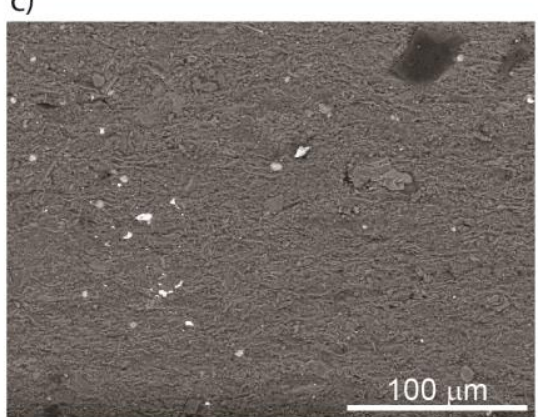

f)

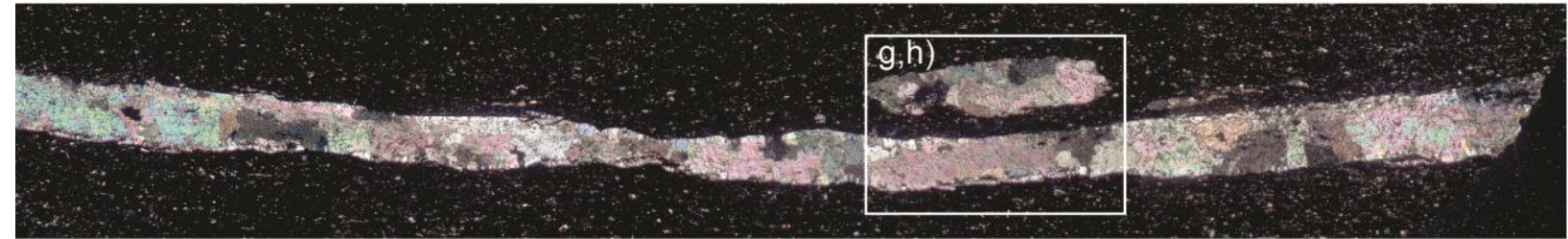

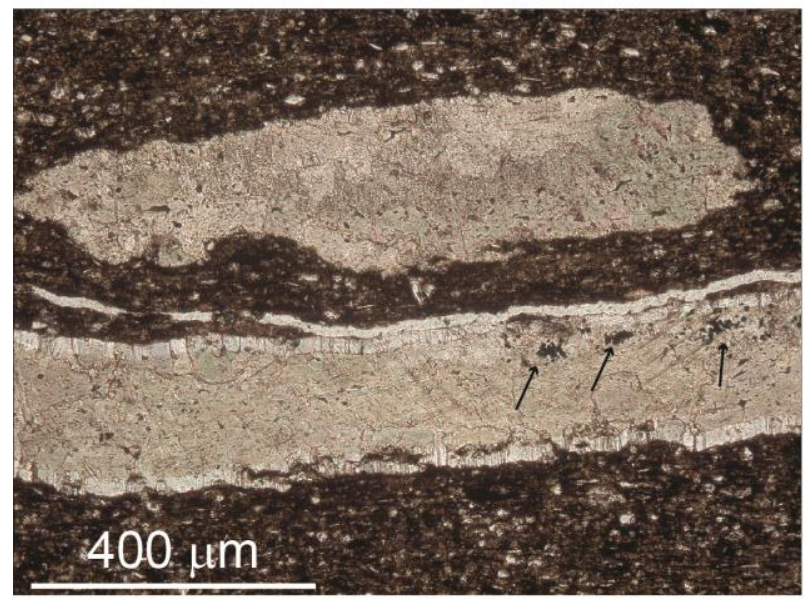

g)

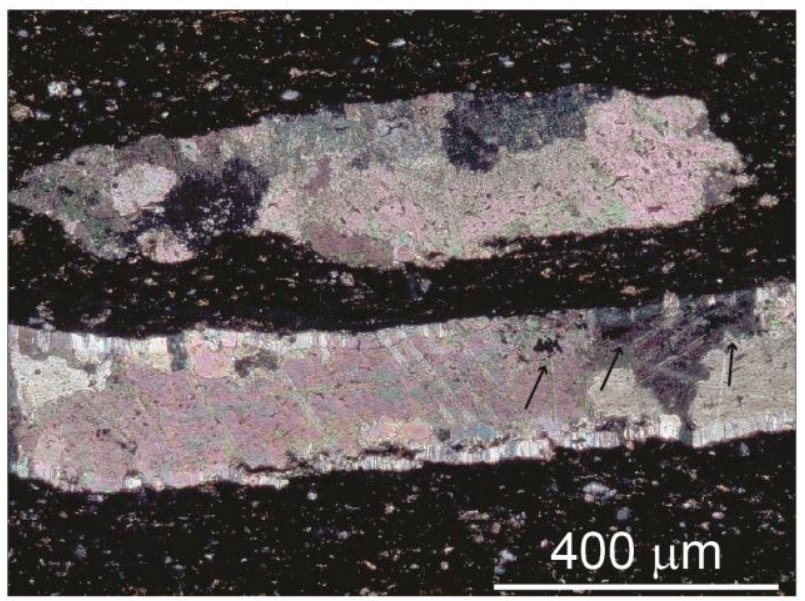

h)

144 Figure 2. Microstructural observations. a-f) Back scatter electron images from the slip surface 145 SQ698.0-SS20 (a-c), and the sample SQ705.3-SS19 (d-f) located closest to the slip surface. a) 146 Close-up of elongated calcite patch, 600x magnification. Striations are omni-present, but more 147 pronounced in the calcite patch. b) 600x magnification. Clay-rich matrix in the center, with 148 visible striations and sub-micron grain size. Coarse fault gouge at the bottom. Silica-rich matrix 149 in the top-left, slightly coarser grained than the clay-rich matrix. c) EDS map of b). d) 200x 150 magnification. Top edge of the channel structure, with bright barite crystals at the edge, mixed 
151 with carbonate. e) EDS image of d). f) 600x magnification. Close-up of the matrix in the channel, 152 with elongated clay particles with random orientation, and visible pore space. g-h) Optical 153 microscope images of the veins in sample SQ685.65-SS7. Note the twinned carbonate crystals. 154 The arrows indicate grouped oxides. g) plane-polarized light. h) cross-polarized light.

\subsection{X-ray microtomography imaging}

156 We have scanned four core samples using a laboratory tomograph (Nikon XT H 225 ST), with a 157 beam energy of $180 \mathrm{kV}$, at voxel sizes of 11 to $26 \mu \mathrm{m}$. We also scanned a subvolume of sample 158 SQ685.65 at $7 \mu \mathrm{m}$ voxel size. A subvolume of this sample has been scanned as well at the 159 beamline ID19 at the European Synchrotron Radiation Facility (ESRF), at two different voxel sizes $(1.7$ and $0.16 \mu \mathrm{m})$, using a beam energy of $40 \mathrm{keV}$. The possibility to separate two objects

161 in the scans when they are located close to each other is roughly twice the voxel size. The 162 decrease in voxel size of the ESRF scans helps distinguish the cracks and veins with better 163 resolution. At the largest voxel size, the complete samples could be imaged, which allowed for 164 an overview of the entire cm-sized sample. With micron voxel sizes the coarsest individual 165 grains are visible, and at sub-micron size we observe the grains in the matrix, as well as some of 166 the intergranular pore space.

167 The 3D images were processed using the software package AvizoFire@ (edition 9), following a 168 new method (described below) to quantitatively determine crack- and vein-geometry and 169 morphology. We isolated crack and vein data of individual features to enable subsequent 170 quantitative analysis of their topography. In order to isolate objects, we traced the matrix-air

171 interface for the cracks, and the vein-matrix interface for the veins. The general procedure for 172 segmenting fractures and veins was to remove the background using a binary mask, after which a 173 non-local-means filter was applied, which is an edge-preserving filter. All samples were 174 processed using the same filter, though the exact parameters were sample-dependent. The details 
175 of the filtering procedure are listed in Table 2. Since in the XCT cores all cracks and veins are

176 oriented parallel to the bedding, we applied the 2-D smoothing filters in the direction

177 perpendicular to the object planes to ensure minimum effect on the fracture roughness.

178 Subsequent use of simple thresholding, where necessary combined with a watershed procedure

179 (Beucher and Meyer, 1992) and/or a region-growing algorithm, enabled us to isolate individual

180 objects, i.e. cracks and veins, following procedures similar to Kobchenko et al. (2011) and

181 Panahi et al. (2012). For some samples it was needed to delete an outer ring voxels of the sample

182 to get rid of beam hardening effects, which effectively decreased sample diameter by $\sim 1 \mathrm{~mm}$.

183 After filtering individual veins and fractures were isolated for subsequent data processing.

184 Table 2. Details of XCT analysis.

\begin{tabular}{|c|c|c|c|c|c|c|c|c|}
\hline $\begin{array}{l}\text { Sample } \\
\text { Code }\end{array}$ & Location & $\begin{array}{l}\text { Voxel size } \\
(\mu \mathrm{m} / \text { voxel })\end{array}$ & $\begin{array}{l}\text { Number } \\
\text { of } \\
\text { extracted } \\
\text { veins }\end{array}$ & $\begin{array}{l}\text { Number } \\
\text { of } \\
\text { extracte } \\
\text { d cracks }\end{array}$ & $\begin{array}{l}\text { pre- } \\
\text { segmentati } \\
\text { on } \\
\text { operations }\end{array}$ & $\begin{array}{l}\text { Filters } \\
\text { calcite }\end{array}$ & $\begin{array}{l}\text { Filters } \\
\text { cracks }\end{array}$ & $\begin{array}{l}\text { Extra } \\
\text { details }\end{array}$ \\
\hline $\begin{array}{l}\text { SQ689.3- } \\
\text { SS5 }\end{array}$ & XCT Oslo & 24.6 & 3 & 1 & $\begin{array}{l}\text { conversion } \\
\text { to 8-bit } \\
\text { unsigned }\end{array}$ & $\begin{array}{l}\text { NLM: } \\
30-10-0.6\end{array}$ & $\begin{array}{l}\text { NLM: } \\
30-5- \\
0.3 \\
\end{array}$ & $\begin{array}{l}\text { Cracks: } \\
\text { tophat filter }\end{array}$ \\
\hline $\begin{array}{l}\text { SQ636.5- } \\
\text { SS11 }\end{array}$ & XCT Oslo & 12.7 & 1 & - & $\begin{array}{l}\text { conversion } \\
\text { to 8-bit } \\
\text { unsigned; } \\
\text { normalize } \\
\text { grayscale }\end{array}$ & $\begin{array}{l}\text { NLM: } \\
21-7-0.4 \\
(2 \mathrm{x})\end{array}$ & $\mathrm{n} / \mathrm{a}$ & $\begin{array}{l}\text { treshold, } \\
\text { use various } \\
\text { region- } \\
\text { growing } \\
\text { algorithms, } \\
\text { watershed }\end{array}$ \\
\hline \multirow[t]{4}{*}{$\begin{array}{l}\text { SQ685.65- } \\
\text { SS7 }\end{array}$} & XCT Oslo & 25.7 & 2 & 2 & $\begin{array}{l}\text { conversion } \\
\text { to 8-bit } \\
\text { unsigned }\end{array}$ & $\mathrm{n} / \mathrm{a}$ & $\begin{array}{l}\text { NLM: } \\
12-7- \\
0.6\end{array}$ & $\begin{array}{l}\text { treshold, } \\
\text { use various } \\
\text { region- } \\
\text { growing } \\
\text { algorithms, } \\
\text { watershed }\end{array}$ \\
\hline & XCT Oslo & 7.8 & - & 1 & $\begin{array}{l}\text { conversion } \\
\text { to 8bit } \\
\text { unsigned; } \\
\text { normalize } \\
\text { grayscale }\end{array}$ & $\mathrm{n} / \mathrm{a}$ & $\begin{array}{l}\text { NLM: } \\
30-10- \\
0.6\end{array}$ & $\begin{array}{l}\text { threshold, } \\
\text { use various } \\
\text { region- } \\
\text { growing } \\
\text { algorithms, } \\
\text { watershed }\end{array}$ \\
\hline & $\begin{array}{l}\text { Synchrotron, } \\
\text { ESRF ID } 19\end{array}$ & 1.7 & - & 1 & 16-bit & $\mathrm{n} / \mathrm{a}$ & $\begin{array}{l}\text { NLM: } \\
8-4-0.8\end{array}$ & $\begin{array}{l}\text { Threshold, } \\
\text { use various } \\
\text { region- } \\
\text { growing } \\
\text { algorithms, } \\
\text { watershed }\end{array}$ \\
\hline & $\begin{array}{l}\text { Synchrotron, } \\
\text { ESRF ID } 19\end{array}$ & 0.16 & - & 1 & 16-bit & $\mathrm{n} / \mathrm{a}$ & $\begin{array}{l}\text { NLM: } \\
15-5- \\
0.9\end{array}$ & $\begin{array}{l}\text { treshold, } \\
\text { use various } \\
\text { region- } \\
\text { growing }\end{array}$ \\
\hline
\end{tabular}




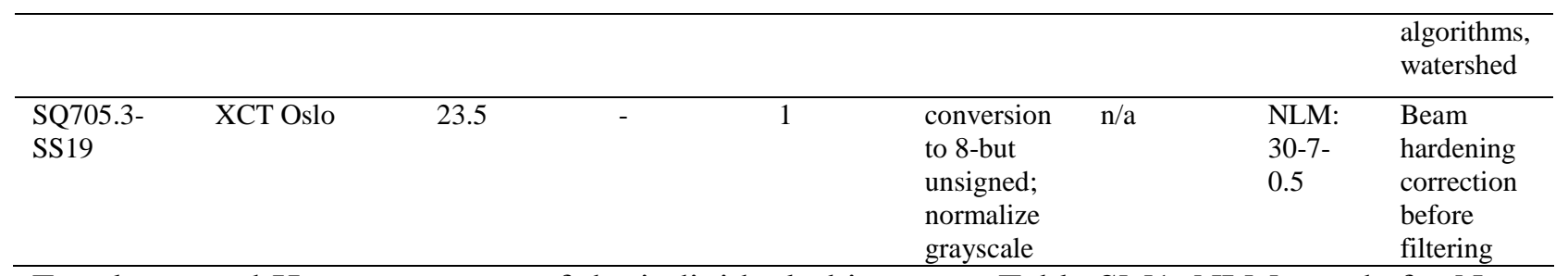

For slopes and Hurst exponents of the individ
Local Means Filter in AvizoFire $@$ software.

\subsection{White light interferometry topography imaging}

The topography of the fractures exposed on the surface of the slabs was measured directly using a white light interferometer (Wyko NT1100) plus Veeco software (Figure 1f; 1h). For these slabs we measure the vein-air interface, and we interpret them to be similar to the matrix/air interface of the open cracks extracted in 3-D with microtomography. The interferometer was placed on a damped table, allowing vertical nanometer resolution. All samples were scanned at 5x and 20x magnification (5x Wyko lens and 20x Leica lens, both with a field of view of 1) and sample SQ631.45-SS15 was imaged at magnifications of 2.5x-5x-10x-20x and 40x. The slip surface sample SQ698.0-SS20 was scanned at all available magnifications, so at 2.5x-5x-10x-20x-25x40x-50x and 100x, with accompanying sampling distances (i.e. pixel size in the height images) between $3.90 \mu \mathrm{m}$ and $94.51 \mathrm{~nm}$. After scanning, the fracture topography data are imported into Matlab. For locations with insufficient light exposure and missing topography data (between 1 and $10 \%$ of the scanned area) the data was interpolated using the standard Matlab function 'griddata'.

\subsection{Data processing}

Once the 2D (white light interferometry) and the individual fractures and veins from the 3D (XCT) data were acquired, we analyzed the topography of the fractures and of the vein-matrix interface. The variation of the height of a surface is called the roughness, and we quantify how 
the roughness amplitude varies with the measurement scale with the Hurst exponent $H$, in order to characterize the spatial correlations in the samples. First, the isolated cracks and veins derived from the XCT data and the WLI data were imported as height fluctuations around a mean plane. The XCT data were subdivided in out-of-plane fluctuations of the top surface, the bottom surface, and the fluctuation of the thickness or aperture (obtained by subtracting the bottom from the top data). Some examples of 1-D height versus distance profiles are given in Figure 3. To determine the Hurst exponent $H$, we have followed the standard steps as outlined in detail by Candela and co-authors (Candela et al., 2009; Candela and Brodsky, 2016). In short, we extracted the height profiles in one direction and removed a linear trend if needed. Since the Fourier transform is the least influenced by the noise of the measurement apparatus and by missing data (Schmittbuhl et al., 1995; Candela et al., 2009), we calculated the Fourier power spectrum density for each profile, which were then averaged across the sample. A power-law fit of the linear part of the Fourier spectra in a log-log plot is performed to extract the Hurst exponent, taking into account only the well-resolved wavenumbers. The minimum wavenumber is related to the size of the surface divided by 2 and corresponds to the Nyquist frequency of the data. The maximum wavenumber is limited by the spatial resolution of the acquisition system (see Appendix Table A1 for wavenumbers of each fit). Candela and Renard (2012) have shown that when $40 \%$ of the datapoints is missing, it will lead to an error of $4 \%$ for the value of $H$, which implies that the error on the analysis of our white light interferometer data (max. $10 \%$ unexposed area) is $<4 \%$.

We have verified our calculation against synthetically randomly generated surfaces (Biermé et al., 2007), showing that our code calculates the same Hurst exponent $( \pm 0.02)$ as the input value. Furthermore, to determine the effect of any geometrical anisotropy, the Hurst exponent of each object is determined in two directions, in the $x$ and y directions of the resulting fracture paths. 


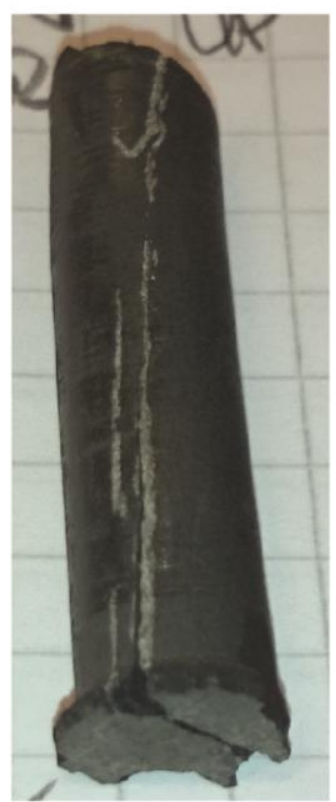

a)

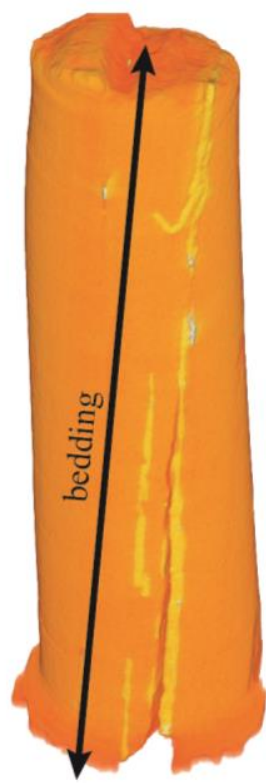

b)

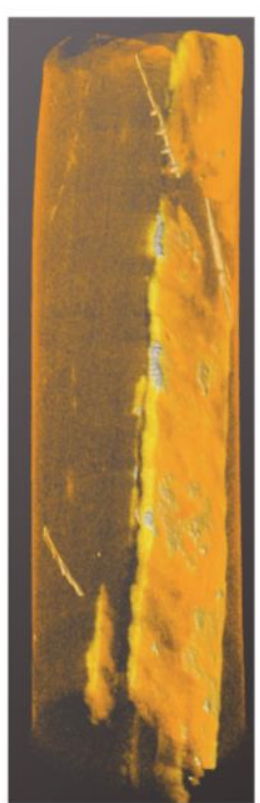

c)

\subsection{Roughness}

\subsubsection{X-ray microtomography data}

At low resolution, we extracted in total thirteen objects, six veins and seven cracks. Example data are shown in Figure 3 and in the 3D models. The results of the Fourier analysis of the top 

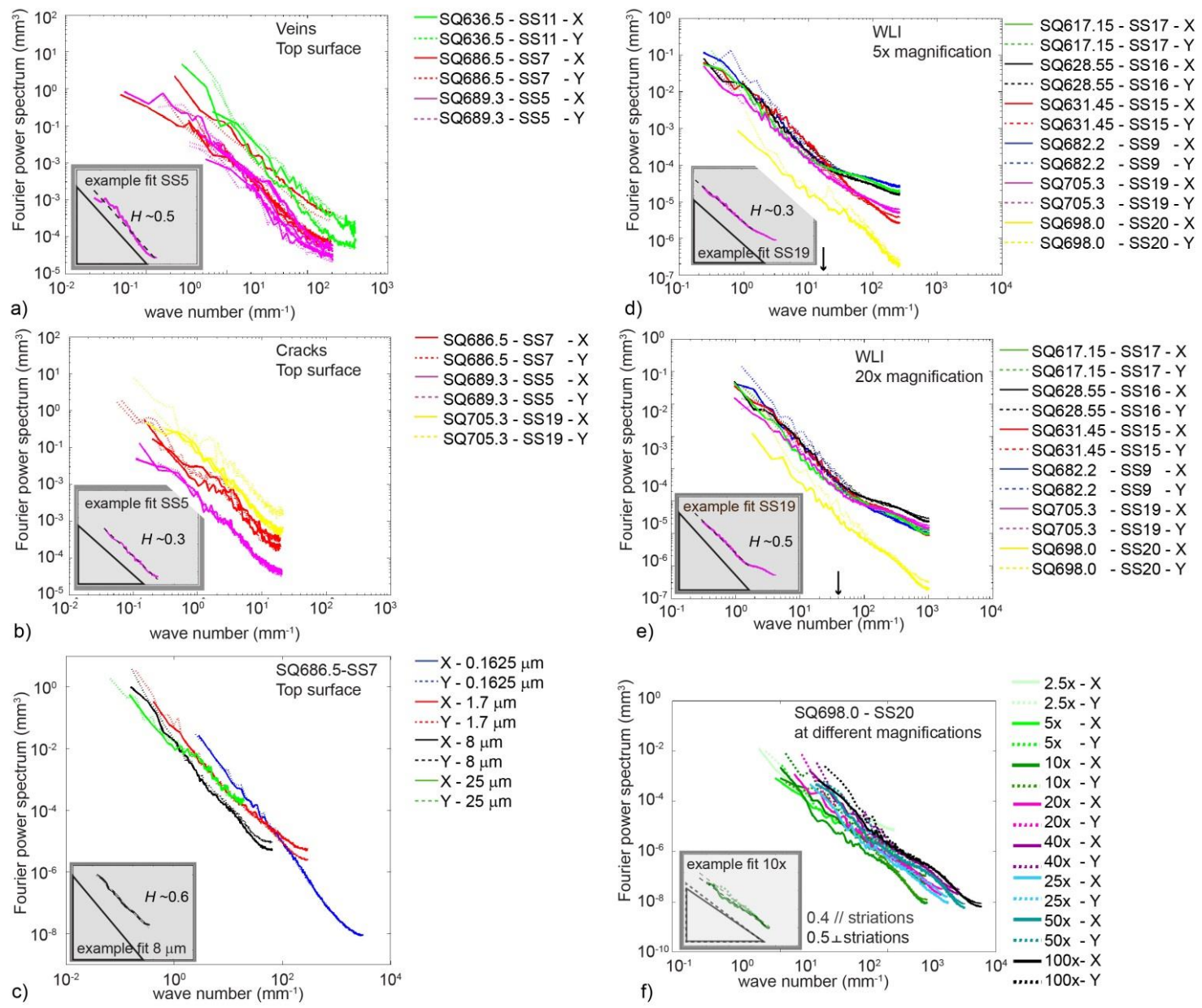

246 Figure 4. Wave number versus Fourier power spectrum for the top surfaces of the veins and cracks obtained from the XCT scans and for white light interferometry. Appendix 1 contains all images plus individual Hurst exponents. The different colors indicate different samples, as shown in the legend. For the XCT data multiple single objects are analyzed from each sample. Each subplot contains an inset with an example fit. a) XCT data; veins; resolution 11-26 $\mu \mathrm{m} /$ voxel. b) XCT data; cracks; resolution 20-26 $\mu \mathrm{m} /$ voxel c) XCT data; crack in sample SQ686.5- SS7 at multiple resolutions. d) WLI data, 5x magnification; sampling distance $1.94 \mu \mathrm{m}$.

253 There is a break in slope at wave number $17.8 \mathrm{~mm}^{-1}$, indicated with an arrow. e) WLI data, 20x 254 magnification; sampling distance $0.495 \mu \mathrm{m}$. There is a break in slope at wave number $39.8 \mathrm{~mm}^{-1}$, 255 indicated with an arrow. f) WLI data, the slip surface of sample SQ698.0-SS20 imaged at 256 multiple magnifications. For this sample $\mathrm{X}$ is parallel to the striations, and $\mathrm{Y}$ is perpendicular to 257 the striations. 
258 At this lower resolution, the 3D data do not exhibit significant difference between top, bottom 259 and differential surfaces (i.e. fracture aperture or vein thickness), nor any difference in slope for 260 the $x$ - or the $y$-direction. Thus there is no significant anisotropy at this scale. Slopes are similar 261 between the different objects, regardless from which sample they were extracted. The intercept 262 of the curve (which is indicative of the magnitude of the out-of-plane fluctuation) differs widely 263 between, and there are no clear trends with object type or direction in intercept value. Since the 264 slope of the power spectrum plot exhibits clear trends, it will therefore be the focus of the present 265 study. The vein-rock interface exhibits a Hurst exponent of $\sim 0.53 \pm 0.11$, and the cracks exhibit $H$ $266 \sim 0.29 \pm 0.1$ (Table 3), showing a significant difference between the roughness exponent of the 267 vein-rock interfaces and exhumation cracks.

269 We have imaged SQ686.5-SS7 at four different spatial scales with 0.16, 1.7, 7.8, and 26 $270 \mu \mathrm{m} /$ voxel. Visual inspection of the data shows that the air/matrix interface and the vein/matrix 271 interface become more detailed with increased imaging resolution. With increased resolution the 272 maximum length scale that can be obtained also decreases, due to the accompanying decrease in 273 the size of the volume imaged. We have extracted the open crack with the highest aperture at all 274 resolutions, and the resulting wave number versus Fourier power spectra are shown in Figure 4c. 275 The roughness curves for the different resolutions overlap, leading to a clear trend over four 276 orders of magnitude of spatial scales. At the resolutions above $0.16 \mu \mathrm{m} / \mathrm{voxel}$ the curves exhibit 277 average Hurst exponents of approximately $0.3 \pm 0.1$ (Figure 5a). In contrast, at the highest 278 resolution of $0.16 \mu \mathrm{m} /$ voxel, the Hurst exponent becomes more uniform, with on average $H=$ $279 \quad 0.51$. 


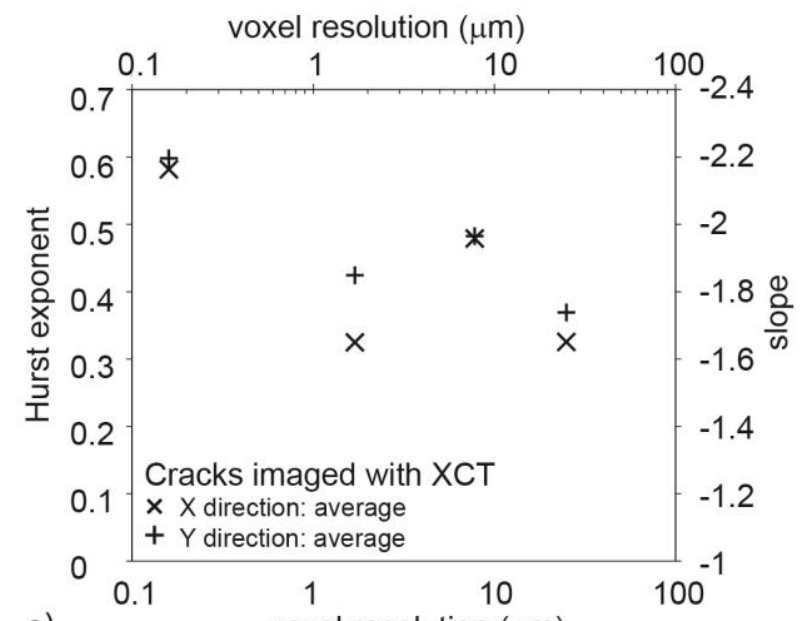

a) voxel resolution $(\mu \mathrm{m})$

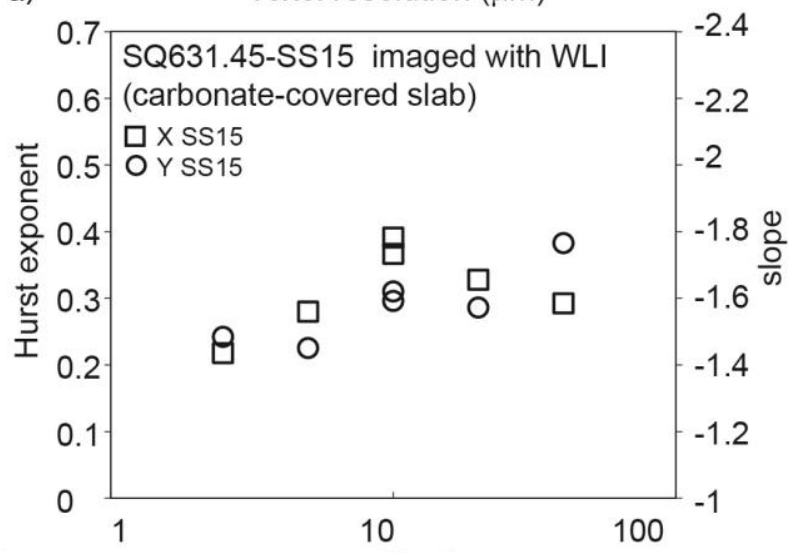

b)

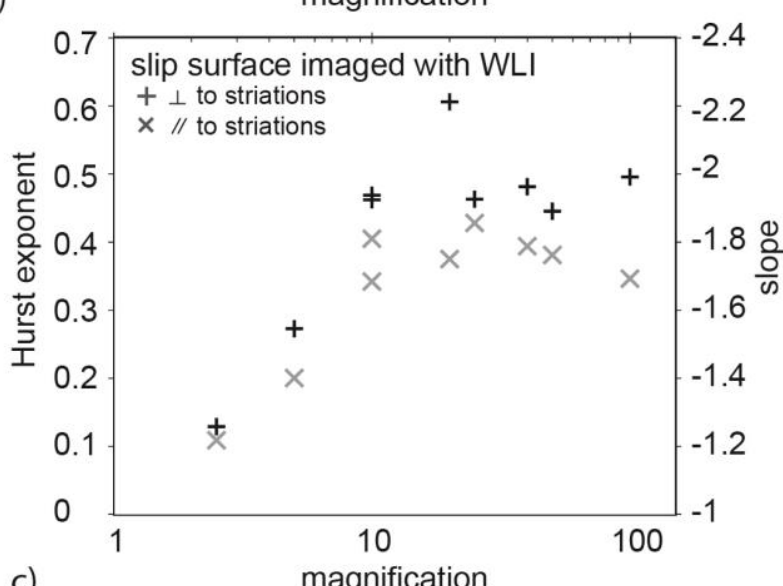

Figure 5. Effect of the scale of the observation. a) For the crack in SQ686.5-SS7 imaged at multiple XCT resolutions in X and Y directions (both roughly parallel to the bedding). b) carbonate-covered slab SQ631.45-SS15 imaged at 2.5 to 40x magnification with the WLI. c) The slip surface imaged at multiple WLI magnifications. At magnifications of $10 \mathrm{x}$ and higher the Hurst exponent is approximately constant and anisotropic; $H=0.38 \pm 0.03$ parallel to striations, and $H=0.49 \pm 0.05$ perpendicular to the striations (see also Figure A6 in Appendix 1). 
Table 3. Slopes and Hurst coefficients.

\begin{tabular}{|c|c|c|c|c|c|}
\hline Analysis & Object & $\begin{array}{l}\text { Resolution / } \\
\text { Magnification }\end{array}$ & Direction & $\begin{array}{l}\alpha \text { (average } \pm \\
\text { standard } \\
\text { deviation) }\end{array}$ & $\boldsymbol{H}$ \\
\hline $\mathrm{XCT}$ & Veins & $12-26 \mu \mathrm{m} /$ voxel & $X$ & $-2.09 \pm 0.19$ & 0.55 \\
\hline $\mathrm{XCT}$ & Veins & $12-26 \mu \mathrm{m} /$ voxel & $Y$ & $-2.03 \pm 0.22$ & 0.52 \\
\hline $\mathrm{XCT}$ & Cracks & $12-26 \mu \mathrm{m} /$ voxel & $\mathrm{Y}$ & $-1.58 \pm 0.15$ & 0.29 \\
\hline $\mathrm{XCT}$ & Cracks & $12-26 \mu \mathrm{m} /$ voxel & $\mathrm{X}$ & $-1.56 \pm 0.19$ & 0.28 \\
\hline WLI & $\begin{array}{l}\text { Open vein } \\
\text { surfaces }\end{array}$ & $\begin{array}{l}5 \mathrm{x} ; \text { sampling distance } \\
1.9 \mu \mathrm{m}\end{array}$ & $\mathrm{X}$ & $-1.54 \pm 0.074$ & 0.28 \\
\hline WLI & $\begin{array}{l}\text { Open vein } \\
\text { surfaces }\end{array}$ & $\begin{array}{l}\text { 5x; sampling distance } \\
1.9 \mu \mathrm{m}\end{array}$ & Y & $-1.59 \pm 0.11$ & 0.30 \\
\hline WLI & $\begin{array}{l}\text { Open vein } \\
\text { surfaces }\end{array}$ & $\begin{array}{l}\text { 20x; sampling distance } \\
0.5 \mu \mathrm{m}\end{array}$ & $\mathrm{X}$ & $-1.86 \pm 0.19$ & 0.43 \\
\hline WLI & $\begin{array}{l}\text { Open vein } \\
\text { surfaces }\end{array}$ & $\begin{array}{l}\text { 20x; sampling distance } \\
0.5 \mu \mathrm{m}\end{array}$ & $\mathrm{Y}$ & $-1.94 \pm 0.28$ & 0.47 \\
\hline WLI & Slip surface & Average $10 x-100 x$ & $\mathrm{X}-\mathrm{I}$ & $-1.76 \pm 0.06$ & 0.38 \\
\hline WLI & Slip surface & Average $10 x-100 x$ & $Y-\perp$ & $-1.98 \pm 0.11$ & 0.49 \\
\hline
\end{tabular}

XCT stands for microtomography, WLI for White Light Interferometry, $\alpha$ is the average slope of all samples, and $H$ stands for the Hurst coefficient. See Table SM1 in the Supplementary Material for the individual values. Note that with respect to $\alpha$, the given average for the XCT data is the average of all possible surfaces, i.e. there is no difference between top, bottom or top - bottom surface.

\subsubsection{White light interferometer data}

294 Because of the clear visual difference in texture between the slabs with a mineral cover and the 295 slab with the slip surface (Figure 1) we treat these separately. The white light interferometry scans of sample SQ631.45-SS15, representative for the calcite-covered samples, are shown in Figure 6, including examples of 1-D profiles (see Appendix 1 for the other surfaces). The wave number versus Fourier power spectra are shown in Figure 4d-f. At 5x magnification (sampling distance $1.9 \mu \mathrm{m}$ ) there is a break in slope at a wave number of $17.8 \mathrm{~mm}^{-1}$ (Figure $4 \mathrm{~d}$ ), 300 corresponding to a length scale of $0.028 \mathrm{~mm}$. At 20x magnification (sampling distance $0.5 \mu \mathrm{m}$ ) 301 there is a break in slope at a wave number of $39.8 \mathrm{~mm}^{-1}$, corresponding to a length scale of 0.013 $302 \mathrm{~mm}$ (Figure 4e). 

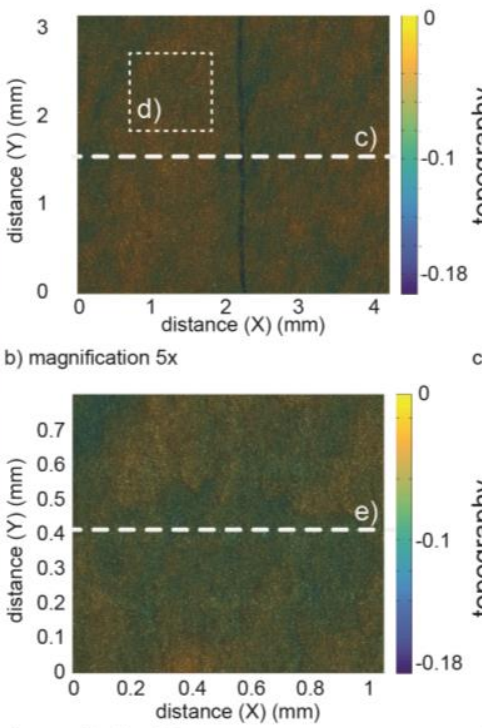

d) magnification $20 x$

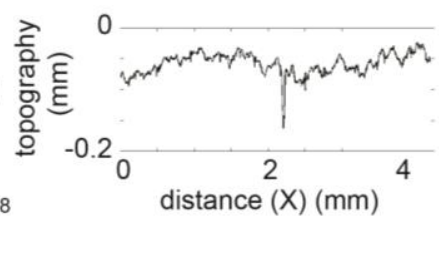

c)

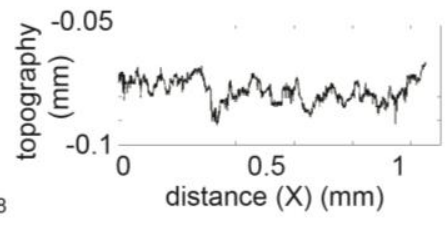

Figure 6. WLI scans on sample SQ631.45-SS15. The scans of the other samples are in the Appendix Figures A5 and A6. a) sample photo. Location of scan shown in b) indicated by the white box. b) WLI scan at 5x magnification (sampling distance $1.94 \mu \mathrm{m}$ ). Location of the profile shown in c) indicated with the white dotted line. Location of the scan shown in d) indicated by the white box. c) Example of 1-D profile along X-direction. d) WLI scan at 20x magnification (sampling distance $0.495 \mu \mathrm{m}$ ). Location of the profile shown in e) indicated with the white dotted line. e) Example of 1-D profile along X-direction.

For length scales shorter than these numbers roughness exponents become lower. SEM-EDS analysis showed barite crystals in the carbonate cover of approximately that size and since barite exhibits strong cleavage, we relate these low roughness exponents to interference between the reflected light from barite cleavage planes and the reference beam in the WLI. Therefore, the slopes reported in Table 3 are for the length scales exceeding 0.029 and $0.013 \mathrm{~mm}$ respectively. The WLI data exhibit similar slopes in both $x$ and $y$ directions, and there is a clear difference between low and high magnification. Note that the slabs are all taken perpendicular to the bedding, so the $x$ and $y$ directions both lie in the plane perpendicular to the bedding. At $5 \mathrm{x}$ magnification, the average Hurst exponent is 0.28 to 0.30 , and at $20 \mathrm{x}$ it is on average 0.43 to 0.47 (Table 3). We imaged the surface of the carbonate-covered slab SQ631.45-SS15 (Figure 6) at 2.5 to $40 \mathrm{x}$ magnification, which indicated little change in roughness with magnification - though a 
322 significant increase in the spread at 20x magnification (as shown by the increased standard

323 deviation in Figure 5b; see also Appendix Table A1).

324 We imaged the slip surface at all possible WLI magnifications, from 2.5-100x. At 2.5x 325 magnification $(3.9 \mu \mathrm{m}$ sampling distance) $H \sim 0.11$ and at $5 \mathrm{x}$ magnification $(1.9 \mu \mathrm{m}$ sampling 326 distance) $H \sim 0.3$ (Table 3, Figure 4f). For magnifications of 10x and more the Hurst exponent is 327 fairly constant as well as strongly anisotropic (Figure $5 b$ ): $H=0.38 \pm 0.03$ parallel to striations, 328 and $H=0.49 \pm 0.05$ perpendicular to the striations. The slope is constant over more than three 329 orders of magnitude of length scales (Figure $4 \mathrm{f}$ ).

\section{4. Discussion}

331 We have shown that roughness values of cracks and veins in the Pomeranian shale can be 332 obtained not only from conventional WLI measurements, but also from segmented XCT images. 333 In the following, we relate the obtained roughness values of the open cracks and discuss the 334 possible origin of the difference between cracks and veins. This is followed by the effect of scale 335 of observation on the roughness, and the implications for modeling flow through fractures in the 336 Pomeranian shale.

\subsection{The roughness of open cracks and the shale microstructure}

338 In general, crack roughness is studied because it is considered as a 'fossil record' of crack 339 propagation, the path of which is determined by the stress field at the crack tip. Following 340 continuum theory of crack growth, a crack propagating in an isotropic solid follows a path so the 341 shear stress at the crack tip is eliminated. For isotropic homogeneous materials, this is described 342 by linear elastic fracture mechanics theory (LEFM; i.e. Bonamy, 2009). $H=0.8$ is in physics 343 frequently reported as the 'universal' roughness value for simple fracture (i.e. little displacement) 
344 of many different (though usually homogeneous) materials, including some rock materials (c.f.

345 Bouchaud, 1997; Renard et al., 2013). The values reported in this paper are much lower, but 346 recently it has been shown that in Fontainebleau sandstone and sintered glass bead-cylinders 347 simple mode I fracture leads to isotropic Hurst exponents of 0.4 (Ponson et al., 2006, 2007). 348 This sandstone is a homogeneous, pure quartz rock, and observations were from the grain scale 349 and up. On a qualitative basis, the open cracks in our heterogeneous shale samples share 350 similarities to the mode I fractures in sandstone, since they, too, are caused by the simple 351 splitting of the core material after exhumation. Our low resolution observations are up to a few 352 tens of microns in scale, i.e. on the same scale as the grainsize of the randomly dispersed strong 353 clasts (quartz, carbonates and feldspar, see also Figure 2f). On this scale, these clasts will have a 354 large influence on the stress field of a crack propagating through the weak, submicron clay 355 matrix. The low value of $H=0.3$ reported here indicates that the crack path in shale is more 356 irregular than the mode I path in the pure sandstone (Ponson et al., 2006, 2007). Even though no 357 controlled experiments have been performed yet on heterogeneous rock materials such as shale, 358 it is interesting to note that on the nanometer scale, atomic force microscopy studies have shown 359 that the roughness exponent in soda-lime-silica glass was 0.18 versus 0.29 in silica glass. This 360 was attributed to the presence of the different ions in the soda-lime-silica glass (Wiederhorn et al., 361 2007), and this deviation in Hurst exponent is similar to the difference $H=0.3$ in shale vs. $H=$ 3620.4 in sandstone for mode I cracking. Differences in material properties, fracture type, pressure, 363 fracture dynamics, temperature, chemistry, and/or deformation mode can lead to a much wider 364 range of roughness exponents than previously thought on the basis of simple fracture mechanics. 365 The microstructure of the Pomeranian shale is fairly typical for shales in general, since shales are 366 defined as rocks that contain about 30\% clays (e.g. Horsrud et al., 1998), where the clay particles 
367 are usually micro-meter sized (Meunier, 2006). This implies that these low Hurst exponents may

368 be more common than previously thought.

\subsection{The difference in roughness between cracks and veins}

Following the analogy to mode I cracking in sandstone, the Hurst exponent of 0.3 for the air/rock interface can be explained by the presence of strong clasts that deviate and randomize the path of a propagating crack. But why does the vein-rock interface, with a Hurst exponent of 0.5, exhibit a less random pattern? We postulate three possible causes: i) the open cracks formed at a different in-situ stress than the veins, ii) the opening mode was different, or iii) there is an evolution effect, either through fluid flow (chemical alteration) or through displacement (mechanical alteration).

First, Griffith crack growth theory states that crack growth only proceeds when the release of mechanical energy exceeds the energy needed to create a new surface. The stress state in the unfractured matrix plays a role in determining the direction of propagating crack (Bonamy, 2009), which implies as well that the initial stress state of a rock may play a role. The open cracks propagated at ambient conditions, i.e. where the rock has relatively little stored elastic energy, so they opened in a different stress field than the veins. It is reasonable that the presence of strong inclusions has a higher impact in determining the direction or the deviation of the crack path than for a rock at depth, when the entire system is already under stress. In other words, if the initial stress state of the intact rock is $\sigma_{i}$, and the stress induced by heterogeneities is $\Delta \sigma$, the ratio of $\Delta \sigma / \sigma_{i}$ is drastically different for the opening of cracks at ambient conditions from opening under in situ stress. In this way the inherently heterogeneous nature of shales may cause the less random nature of the cracks opening in the subsurface. 
Second, the simple splitting of the shale to form the open cracks likely corresponds to simple mode I opening. For the veins, the large crystals in the center of the veins (Figure $2 \mathrm{~g}$-h) are indicative of initial mode I crack opening thereby allowing for slow crystal growth. The small crystals along the side indicate that this phase is followed by a reactivation phase with fluid flow along the vein/matrix interface. However, opening under a confining pressure usually introduces a shear component as well (Bonamy, 2009), and therefore it seems unlikely that tensile opening of subsurface cracks will be pure mode I. It is possible that the difference in roughness between veins and crack is (partially) an effect of pure mode I opening combined with a small shear component for the veins versus simple mode I for the cracks. Most Hurst exponents in the literature are measured on mode I cracks (Bouchaud, 1997). When considering mode II fractures, the shear on the fracture induces usually some anisotropy, which develops as slip increases (Amitrano and Schmittbuhl, 2002). Finally, when considering a fault surface, the anisotropy is 401 pronounced at all scales (Renard et al., 2006; Candela and Renard, 2012). So a difference of 402 Hurst exponent between mode I and mode II fractures and faults is expected, where the 403 anisotropy of the Hurst exponent with direction will be larger for mode II slip surfaces than for 404 mode I fractures.

405 Comparison between the values from the vein/rock interface to those obtained for the slip surface 406 of sample SQ698.0-SS20 helps to constrain if there is an evolution effect. Striations on this 407 surface are omnipresent (Figure 2; Appendix Figure A6), introducing a clear textural anisotropy. 408 The roughness of the slip surface in itself was lower than the roughness reported for the strongly 409 striated slip surfaces reported by Candela and Renard (2012), which we interpret as an effect of 410 small displacement (Sagy et al., 2007; Brodsky et al., 2011). Since the vein/rock interface was 411 perfectly isotropic, this implies there was no or very little mechanical alteration of the interface. 
412 The approximate match in roughness values of the striated surface and the vein-rock interface

413 imply that the mechanical and chemical evolution only have small effects on the roughness of

414 cracks opening in the subsurface.

415 We have summarized our observations and the possible causes in Figure 7. The most likely 416 causes of differences between cracks and veins are either the difference in opening mode and/or

417 the difference in in-situ stress. Both of these explanations imply that cracks that open at depth in

418 shales produce a different roughness than those opening at ambient conditions. This indicates

419 that the Hurst roughness exponent can be a microstructural criterion to determine between

420 exhumation and in-situ fractures. To be fully confident this could be extrapolated to other shales

421 more research is required, though there seem to be no a priori reasons why the aforementioned

422 principles/mechanisms would not apply to other drill core shales.

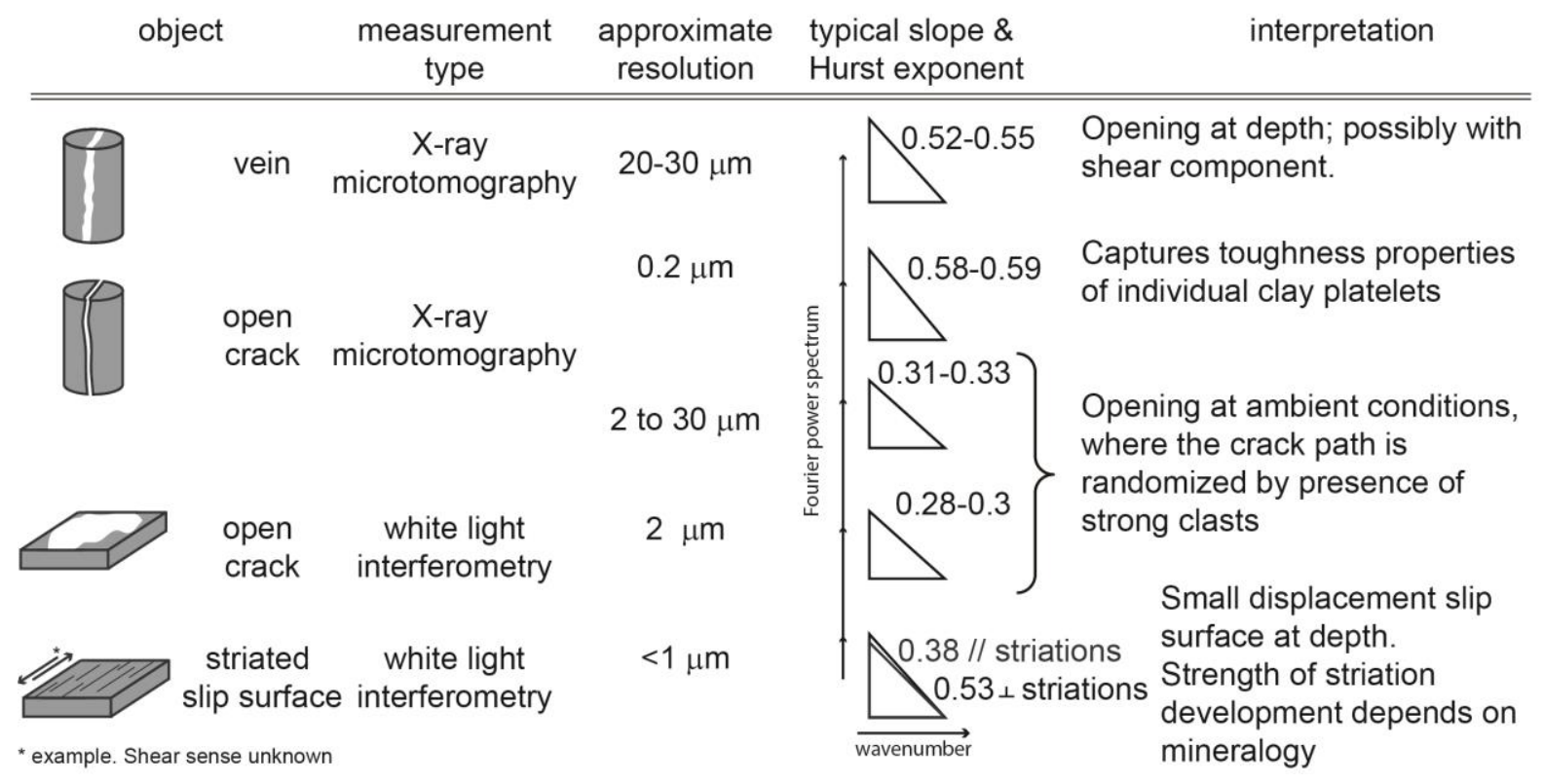

424 Figure 7. Summary of observations and interpretations. The Hurst values indicated in the table 425 represent the range of average values for each object type. 


\subsection{The effect of scale}

427 Following Ponson et al (2007) and taking the shale microstructure into account, we can also 428 explain the increase in Hurst exponent with increased scale of observation from 0.3 to 0.51 for 429 open cracks and from 0.3 to $0.4-0.5$ for the slip surface (Figure 5a, 5c). At small length scale 430 ('the process zone'), fractures develop from growth and coalescence of small-scale defects. At 431 larger length scales, the characteristics of the fracture surface are determined by the fully brittle 432 manner of continuous crack propagation, and the final roughness is controlled by the toughness 433 distribution at the microscale (Ponson et al., 2007). Translating this concept to fine-grained 434 shales, it is only at the sub-micron scale that the toughness properties of the fine-grained, weak 435 clay platelet topography are captured. At the micron scale and above, crack propagation is 436 controlled by the properties of the heterogeneous distribution of large, strong clasts in an 437 anisotropic fine-grained matrix, but at the submicron resolution the clay platelets data determine 438 material toughness and therefore crack path $(H \sim 0.51$ for high resolution XCT data). A similar 439 argument explains why the Hurst exponent for the carbonate cover does not change with 440 increased magnification (Figure 5b), since the largest sampling distance of $3.9 \mu \mathrm{m}$ 441 (magnification 2.5x) is on the same order as the grain size of the carbonate grains. A decrease in 442 sampling distance therefore does not change the type of properties captured. In contrast, when 443 considering the slip surface there is a significant effect of magnification (Figure 5c). With a low 444 resolution (i.e. magnifications below 10x, or scanning distances above 1 micron), the exponent 445 obtained is representative of the spatial distribution of the patchy localities of fault gouge (Figure 446 2b). To capture the anisotropy related to topography of the slickensides, the resolution must be 447 chosen high enough so that the slickensides and their spacing represent a significant part of the 448 topographic signal. 
449 The interplay between roughness and processes which each have their own scale causes the 450 change in Hurst exponent when changing the measurement resolution. Different effects are 451 captured when changing the resolution, since increased spatial resolution usually comes with 452 decreased sample size. To decide on the resolution needed to reliably determine the Hurst 453 exponent, first the size of the smallest element of interest needs to be determined (i.e. the 454 structure and grain size of the material), which becomes particularly important in polymineralic 455 materials. Different mineral grains will lead to different fracture patterns on the grain scale, 456 which corresponds to differences in strength on the grain scale as well. Ultimately, imaging and 457 roughness determination need to be done at a resolution that is appropriate for the feature of 458 interest, i.e. taking the microstructure into account.

\subsection{Implications}

460 From a geoengineering perspective, the main interest in the roughness of these fractures stems

461 from the need to accurately model fluid flow in (open) fractures at depth. For these purposes it is

462 important to understand the roughness one could expect for fractures at depth in tight rock 463 formations (Noiriel et al., 2007; Fitts and Peters, 2013). For an engineered fracture the expected 464 fracturing mode would be tensile opening of the formation at depth, probably with a small 465 component of shear displacement. Comparing such a fracture to the types of fractures studied 466 here, it would be the striated surface and the vein-rock interface which would have a more 467 representative history. On this basis, we propose a Hurst exponent $H$ in the range 0.4 to 0.5 as 468 most representative for (induced) fractures in the Pomeranian shale. If a flow model is finely 469 enough meshed and only covers an area comparable in size to that of the high resolution XCT 470 scan ( $<1 \times 1 \mathrm{~mm}$, see Figure A4), a value representative for the clay structure, up to 0.6 could be 471 used. At larger areas the randomizing effect of the heterogeneous distribution of the strong 
472 feldspar, quartz and carbonate clasts should be taken into account. However, since many

473 different types of shale exist, with as many different applications, we call for more roughness

474 studies on these strongly heterogeneous and anisotropic geo-materials, especially considering

475 that the values presented here differ significantly from other rocks investigated so far.

476 With respect to the possible apertures of a fracture, the out-of-plane fluctuations of the vein-rock

477 interface as observed with XCT are locally up to $0.3 \mathrm{~mm}$. However, it is not possible to correlate

478 this one-on-one with aperture values, since the XCT data do not provide direct information on

479 timing, and the microstructures of sample SQ685.65-SS7 (Figure 2g-h) indicate multiple phases

480 of opening and precipitation. For the data presented here it is the single striated slip surface

481 which would be the most representative sample for fresh fractures at depth in shale. At low

482 magnifications (i.e. relatively large surface area, $2.5 \times 2 \mathrm{~mm}$ ), it still exhibited out-of-plane

483 fluctuations of $0.1 \mathrm{~mm}$ (Appendix Figure A6). The SEM images indicated this is probably

484 related to the presence of fault gouge that adheres to the surface. This is to our knowledge the

485 first measurement of topography on a fresh shale sample representative for low displacement

486 fractures. Assuming this single surface is indeed representative for unmated surfaces at depth, it

487 indicates that minimum apertures for low displacement induced fractures up to $100 \mu \mathrm{m}$ are 488 plausible.

489 5. Conclusions

490 Shales can be caprock and source rock both, where their permeability and transport properties 491 are controlled by the presence of microfractures. Most shales weather easily, so the most pristine 492 samples are usually those obtained from boreholes. However, one of the major challenges with 493 borehole samples is to determine which fractures are present in-situ and which are caused by 494 sample handling. In this study, we determined the roughness of open exhumation/drying cracks 
495 as well as intact vein-rock interfaces plus one striated slip surface in Pomeranian shale samples

496 obtained from $4 \mathrm{~km}$ depth. We used the new method of X-ray micro-tomography as well as

497 conventional white light interferometry and found the following:

498

499

500

501

502

503

504

505

506

507

508

509

510

511

512

513

514

515

516

517

- Roughness values obtained with both methods are consistent, which indicates that the 3-

D data obtained from microtomography scans can indeed be used to extract quantitative properties on the roughness of the vein/rock and fracture/matrix interface.

- Open cracks in shale and in veins exhibit Hurst exponents of $0.3 \pm 0.1$ and $0.5 \pm 0.1$ respectively. The two most likely causes of this difference are the difference in opening mode and/or the difference in in-situ stress, which implies that the Hurst roughness exponent can be a microstructural criterion to determine between exhumation and in-situ fractures. To be fully confident this could be extrapolated to other shales more research is required, though there seem to be no a priori reasons why the aforementioned principles/mechanisms would not apply to other drill core shales.

- For fine-grained heterogeneous rock such as shale the Hurst roughness exponent changes with scale of observation, which is related to the microstructure. Imaging and roughness determination should be performed done at a resolution that is appropriate for the feature of interest, i.e. keeping the microstructure in mind.

- We propose a Hurst exponent $H$ in the range 0.4 to 0.5 as most representative for (induced) fractures in the Pomeranian shale, since they form in a more similar fashion as the striated surface and the vein-rock interface.

\section{Acknowledgements}

We thank Jacek Szczepański for the information regarding chemical composition, Elodie Boller at the European Synchrotron Radiation Facility and Øyvind Hammer at the Natural History

Published in Journal of Structural Geology 94, 2017, p. 87-97; https://doi.org/10.1016/j.jsg.2016.11.005 
Museum in Oslo for X-ray tomography scans, André Niemeijer at Utrecht University for microscope access, and Marcin Dabrowski and Dag Dysthe for discussions. We thank the Editor, Toru Takeshita, and Auke Barnhoorn plus an anonymous reviewer for their constructive comments. The raw data obtained with XCT and WLI plus the codes to generate the roughness values are available upon request.

\section{Funding Source}

A.P. and F.R. are funded by ShaleSeq and the Norwegian Research Council [grant number POL-

NOR 234198/100/2014]. M.K. is supported by Statoil.

\section{References}

Amitrano, D., Schmittbuhl, J., 2002. Fracture roughness and gouge distribution of a granite shear band. J. Geophys. Res. Solid Earth 107, ESE 19-1-ESE 19-16. doi:10.1029/2002JB001761

Beucher, S., Meyer, F., 1992. The morphological approach to segmentation: the watershed transformation, in: Optical Engineering. New York Marcel Dekker Incorporated, pp. 433481.

Biermé, H., Meerschaert, M.M., Scheffler, H.-P., 2007. Operator scaling stable random fields. Stoch. Process. their Appl. 117, 312-332. doi:10.1016/j.spa.2006.07.004

Bonamy, D., 2009. Intermittency and roughening in the failure of brittle heterogeneous materials. J. Phys. D. Appl. Phys. 42, 214014. doi:10.1088/0022-3727/42/21/214014

Bouchaud, E., 1997. Scaling properties of cracks. J. Phys. Condens. Matter 9, 4319-4344. doi: $10.1088 / 0953-8984 / 9 / 21 / 002$

Brodsky, E.E., Gilchrist, J.J., Sagy, A., Collettini, C., 2011. Faults smooth gradually as a function of slip. Earth Planet. Sci. Lett. 302, 185-193. doi:10.1016/j.epsl.2010.12.010

Brown, S.R., 1987. Fluid flow through rock joints: the effect of surface roughness. J. Geophyiscal Res. - Solid Earth 92. doi:10.1029/JB092iB02p01337

Candela, T., Brodsky, E.E., 2016. The minimum scale of grooving on faults. Geology 44, 603606. doi:10.1130/G37934.1

Candela, T., Renard, F., 2012. Segment linkage process at the origin of slip surface roughness: Evidence from the Dixie Valley fault. J. Struct. Geol. 45, 87-100. doi:10.1016/j.jsg.2012.06.003

Candela, T., Renard, F., Bouchon, M., Brouste, A., Marsan, D., Schmittbuhl, J., Voisin, C., 2009. 
Characterization of Fault Roughness at Various Scales: Implications of Three-Dimensional High Resolution Topography Measurements. Pure Appl. Geophys. 166, 1817-1851. doi:10.1007/s00024-009-0521-2

Fitts, J.P., Peters, C.A., 2013. Caprock Fracture Dissolution and CO2 Leakage. Rev. Mineral. Geochemistry 77, 459-479. doi:10.2138/rmg.2013.77.13

Horsrud, P., Sønstebo, E.F., Bøe, R., 1998. Mechanical and Petrophysical Properties of North Sea Shales. Int. J. Rock Mech. Min. Sci. 35, 1009-1020. doi:10.1016/S01489062(98)00162-4

Kobchenko, M., Panahi, H., Renard, F., Dysthe, D.K., Malthe-Sørenssen, A., Mazzini, A., Scheibert, J., Jamtveit, B., Meakin, P., 2011. 4D imaging of fracturing in organic-rich shales during heating. J. Geophys. Res. 116, B12201. doi:10.1029/2011JB008565

Meunier, A., 2006. Why are clay minerals small? Clay Miner. 41, 551-566. doi:http://dx.doi.org/10.1180/0009855064120205

Noiriel, C., Madé, B., Gouze, P., 2007. Impact of coating development on the hydraulic and transport properties in argillaceous limestone fracture. Water Resour. Res. 43, W09406. doi:10.1029/2006WR005379

Panahi, H., Meakin, P., Renard, F., Kobchenko, M., Scheibert, J., Mazzini, A., Jamtveit, B., Malthe-Sorenssen, A., Dysthe, D.K., 2012. A 4D Synchrotron X-Ray-Tomography Study of the Formation of Hydrocarbon- Migration Pathways in Heated Organic-Rich Shale. SPE J. 18, 366-377. doi:10.2118/162939-PA

Ponson, L., Auradou, H., Pessel, M., Lazarus, V., Hulin, J.P., 2007. Failure mechanisms and surface roughness statistics of fractured Fontainebleau sandstone. Phys. Rev. E. Stat. Nonlin. Soft Matter Phys. 76, 36108. doi:10.1103/PhysRevE.76.036108

Ponson, L., Auradou, H., Vié, P., Hulin, J.-P., 2006. Low self-affine exponents of fractured glass ceramics surfaces. Phys. Rev. Lett. 97, 125501. doi:10.1103/PhysRevLett.97.125501

Renard, F., Candela, T., Bouchaud, E., 2013. Constant dimensionality of fault roughness from the scale of micro-fractures to the scale of continents. Geophys. Res. Lett. 40, 83-87. doi:10.1029/2012GL054143

Renard, F., Voisin, C., Marsan, D., Schmittbuhl, J., 2006. High resolution 3D laser scanner measurements of a strike-slip fault quantify its morphological anisotropy at all scales. Geophys. Res. Lett. 33, L04305. doi:10.1029/2005GL025038

Sagy, A., Brodsky, E.E., Axen, G.J., 2007. Evolution of fault-surface roughness with slip. Geology 35, 283. doi:10.1130/G23235A.1

Schmittbuhl, J., Vilotte, J.-P., Roux, S., 1995. Reliability of self-affine measurements. Phys. Rev. E 51, 131-147. doi:10.1103/PhysRevE.51.131

Scholz, C.H., 2002. The mechanics of earthquakes and faulting. Cambridge University Press, Cambridge. 
Schulz, H.-M., Horsfield, B., Sachsenhofer, R.F., 2010. Shale gas in Europe: a regional overview and current research activities. Geol. Soc. London, Pet. Geol. Conf. Ser. 7, 1079-1085. doi:10.1144/0071079

Wiederhorn, S.M., López-Cepero, J.M., Wallace, J., Guin, J.-P., Fett, T., 2007. Roughness of glass surfaces formed by sub-critical crack growth. J. Non. Cryst. Solids 353, 1582-1591. doi:10.1016/j.jnoncrysol.2007.01.029 